\title{
Anti-oxidation and Infrared Characteristics of ZrSiO4 Coating
}

\author{
Yang Wang, Zhaofeng Chen ${ }^{\mathrm{a}}$ and ShengJie Yu \\ College of Materials Science and Technology, Nanjing University of Aeronautics and Astronautics, Nanjing 210016, \\ P.R. China
}

\begin{abstract}
In this paper, preparation and properties of $\mathrm{ZrSiO} 4$ coating prepared by pressureless sintering coated carbon/carbon $(\mathrm{C} / \mathrm{C})$ composites and the effect of different temperature on coating in $3-5 \mu \mathrm{m}$ and $8-12 \mu \mathrm{m}$ infrared emissivity were studied. The composition and structure of the $\mathrm{ZrSiO} 4$ coatings were examined by XRD and SEM that showed the main phase was $\mathrm{ZrSiO} 4$. With the addition of mineralizer, $\mathrm{ZrSiO} 4$ synthesis rate increased from $68.58 \%$ to $83.47 \%$. The anti-oxidant performance of the prepared $\mathrm{SiC}$ layer and $\mathrm{SiC}-\mathrm{ZrSiO} 4$ coating at $1500{ }^{\circ} \mathrm{C}$ in air for $24 \mathrm{~h}$ with a mass loss was $1.5 \%$ and $0.4 \%$, respectively. In addition, the experimental results indicated that the emissivity of $\mathrm{ZrSiO} 4$ coating declined with the decrease of $\mathrm{ZrO} 2$, and the infrared emissivity of $\mathrm{ZrSiO} 4$ coating in the $3-5 \mu \mathrm{m}$ and $8-14 \mu \mathrm{m}$ wavebands was 0.55 and 0.64 at $50^{\circ} \mathrm{C}, 0.18$ and 0.43 at $300^{\circ} \mathrm{C}, 0.35$ and 0.74 at $500^{\circ} \mathrm{C}$, respectively.
\end{abstract}

\section{Introduction}

In recent years, the rapid development of aerospace technology and modern needs of war, has led to the continuous improvement of Mach number of flights. Aircraft parts that undergo aerodynamic heating need to withstand more high temperature and thermal shock during flight. Hence, high temperature resistant and low emissivity materials play an important role in modern weapon system [1]. Infrared stealth includes near-infrared $(1-2.7 \mu \mathrm{m})$, mid-infrared $(3-5 \mu \mathrm{m})$, and far infrared $(8-14$ $\mu \mathrm{m})$ three atmospheric windows. Among these, 3-5 $\mu \mathrm{m}$ and 8-14 $\mu \mathrm{m}$ wavebands are the most important infrared detected wavebands [2]. $\mathrm{ZrSiO} 4$ is a tetragonal structure with the islands of silicate minerals. Due to its high melting point, low thermal conductivity, low thermal expansion coefficient, excellent chemical and phase stability and other characteristics, $\mathrm{ZrSiO} 4$ is widely used in the hightemperature environment. Moreover, sintered $\mathrm{ZrSiO} 4$ has excellent thermal shock resistance. It is therefore an important candidate for high temperature structural ceramic materials $[3,4]$.

$\mathrm{ZrSiO} 4$ has rarely been reported as a high-temperature ceramic coating, especially considering the infrared stealthy characteristic and the traditional technologies, such as chemical vapor deposition, plasma or thermal spraying, sol-gel andelectrophoretic deposition. The preparation of $\mathrm{ZrSiO} 4$ coatings is complex, and the production cycles are long, making it not suitable for large complex shape components. Hence, pressureless sintering $\mathrm{ZrSiO} 4$ coating is a good choice. This paper describes a pressureless sintering method for synthesizing $\mathrm{ZrSiO} 4$ ceramic coatings and a preliminary investigation was undertaken to measure the performance of the coating.

\footnotetext{
${ }^{a}$ Corresponding author : zhaofeng_chen@163.com
} 


\section{Experimental details}

Small specimens $(100 \times 100 \times 5 \mathrm{~mm} 3)$ as substrates were cut from bulk $2 \mathrm{D}-\mathrm{C} / \mathrm{C}$ composites (prepared in Changsha China) with a density of $1.70 \mathrm{~g} / \mathrm{cm} 2$. Before the coating process, the specimens were cleaned using ultrasonic cleaner for 5 min, and dried at $100{ }^{\circ} \mathrm{C}$ for $2 \mathrm{~h}$. SiC bonding coating was prepared by a method of CVD (Chemical Vapor Deposition) for $10 \mathrm{~h}$. An SiC coating structure was achieved with a thickness of about $20 \mu \mathrm{m}$.

After the preparation of the $\mathrm{SiC}$ buffer layer, an in-situ formation process was conducted. $\mathrm{ZrSiO} 4$ coating was prepared using the optimal sintering additive $\mathrm{MgO}$. The commercially available powders of $\mathrm{MgO}, \mathrm{ZrO} 2$ and $\mathrm{SiO} 2$ are of analytical grade with a particle size from 1 to $4 \mu \mathrm{m}$. Raw materials formula are shown in Table 1, which $\mathrm{LiF}$ and $\mathrm{CaCl} 2$ are used as mineralizer.

Table 1. Raw materials formula.

\begin{tabular}{|c|c|c|c|c|c|}
\hline Formula & $\mathbf{Z r O}_{\mathbf{2}}$ & $\mathbf{S i O 2}$ & $\mathbf{M g O}$ & $\mathbf{L i F}$ & $\mathbf{C a C l}_{\mathbf{2}}$ \\
\hline $\mathrm{ZS}-1$ & 123 & 72 & 5.85 & $/$ & $/$ \\
\hline $\mathrm{ZS}-2$ & 123 & 72 & 5.85 & 1.95 & 3.9 \\
\hline
\end{tabular}

The starting powders were mixed for $12 \mathrm{~h}$ by ball milling in water-free ethanol with an agate media, and then dried at $70^{\circ} \mathrm{C}$ for $12 \mathrm{~h}$. First, a slurry of powders was applied to the SiC coating surface. It was made by mixing the powders, distilled water and a little PVB (polyvinylbutyral) (0.5 1wt.\%) binder.

After applying the slurry to the surface of the $\mathrm{SiC}$ bonding layer, the samples were dried in air for sufficient time. Finally, the pressureless sintering of bar samples was conducted in a high-temperature furnace with with $1 \mathrm{~atm}$ argon gas, by heating at a ramp rate of $5^{\circ} \mathrm{C} \cdot \mathrm{min}-1$ from room temperature to $500^{\circ} \mathrm{C}$ and then heating at a ramp rate of $10^{\circ} \mathrm{C} \cdot \min -1$ to $1500^{\circ} \mathrm{C}$, holding for $1.5 \mathrm{~h}$ at this temperature to transfer into $\mathrm{ZrSiO} 4$.

After sintering, the preparation of $\mathrm{ZrSiO} 4$ coating was applied directly to the surface of $\mathrm{SiC}$ coating. Product phases were characterised by X-ray diffraction (XRD) using a D/MAX-RB diffractometer and $\mathrm{CuK}$ a 1 radiation for the range $15^{\circ} \sim 80^{\circ}$ in $2 \theta$ with a step-width of $0.02^{\circ}$. The morphologies of the as-prepared multi-layer coatings were analyzed using JEOL-6360LV scanning electron microscope (SEM). The anti-oxidation property of the $\mathrm{ZrSiO} 4$ coating was studied at $1500^{\circ} \mathrm{C}$ using tubular oxidation furnace (Type SK- $1600^{\circ} \mathrm{C}$, Tianjin, China). Using emissivity measuring instrument, the average infrared emissivity of samples was measured at different temperatures in the 3-5 $\mu \mathrm{m}$ and 8-14 $\mu \mathrm{m}$ (Test in Xi'an Institute of Applied Optics).

\section{Results and discussion}

\subsection{Composition and Structure Analysis}

Fig. 1 shows the XRD spectrum of ZS-1 and ZS-2 formulas. It was found that both of the main phases were $\mathrm{ZrSiO} 4$, though a small amount of $\mathrm{ZrO} 2$ and $\mathrm{SiO} 2$ were detected. But compared to the $\mathrm{ZS}-1$ formula, ZS-2 formula relative intensity of $\mathrm{ZrO} 2$ and $\mathrm{SiO} 2$ is significantly lower than $\mathrm{ZS}-1$ formula with higher relative intensity of $\mathrm{ZrSiO}$. This is because on the basis of $\mathrm{ZS}-1$ formula, $\mathrm{ZS}-2$ formula accordingly added a little mineralizer which are $\mathrm{LiF}$ and $\mathrm{CaCl} 2$, improving the conversion rate of $\mathrm{ZrSiO} 4$ obviously. From the chemical reaction dynamics analysis, the role of mineralizer is mainly due to the formation of active reactive groups in the synthesis process, thereby reducing the activation energy. So the synthesis rate of $\mathrm{ZrSiO} 4$ increase at a certain temperature [5]. R. A. Epplerm [6] first quoted famous symbol method to study the ion diffusion problems, and thus explained the mechanism of how the mineralizer to improve zirconium silicate synthesis rate. By using the following formula to calculate a relative content of $\mathrm{ZrSiO} 4$ phase: 


$$
\mathrm{W}=\mathrm{Ai} / \sum \mathrm{Aij} * 100 \%
$$

Where $\mathrm{Ai}$ is the relative integral area of $\mathrm{ZrSiO} 4$ strongest peak and Aij the sum of the relative integral area of all phases strongest peak.

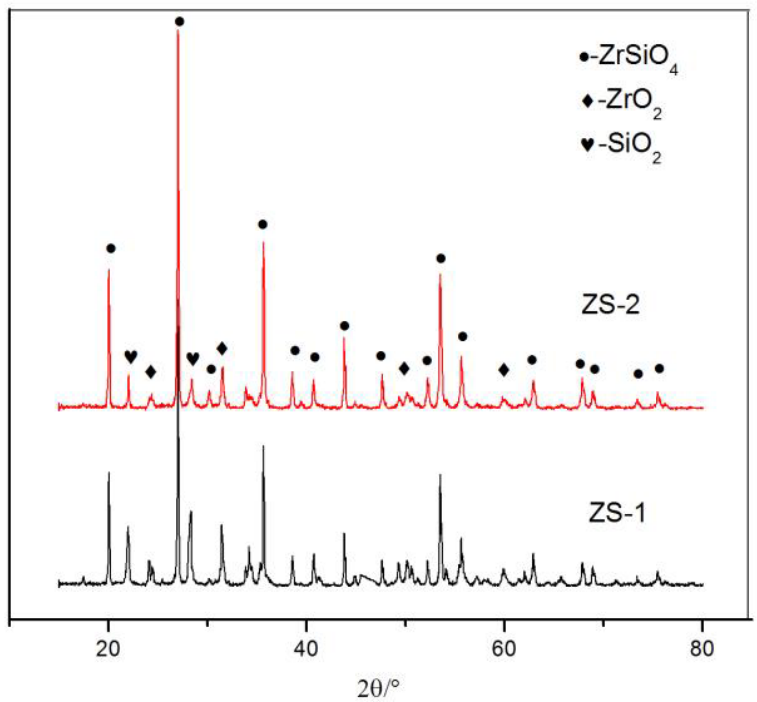

Figure 1. $\mathrm{XRD}$ spectrum of the $\mathrm{ZrSiO} 4$ coating.

From XRD analysis calculations, the peak integral area and relative content of $\mathrm{ZrSiO} 4$ prepared from ZS-1 formula and ZS-2 formula are about $68.58 \%$ and 83.47 , respectively. So with the addition of mineralizer, $\mathrm{ZrSiO} 4$ synthesis rate increased obviously.
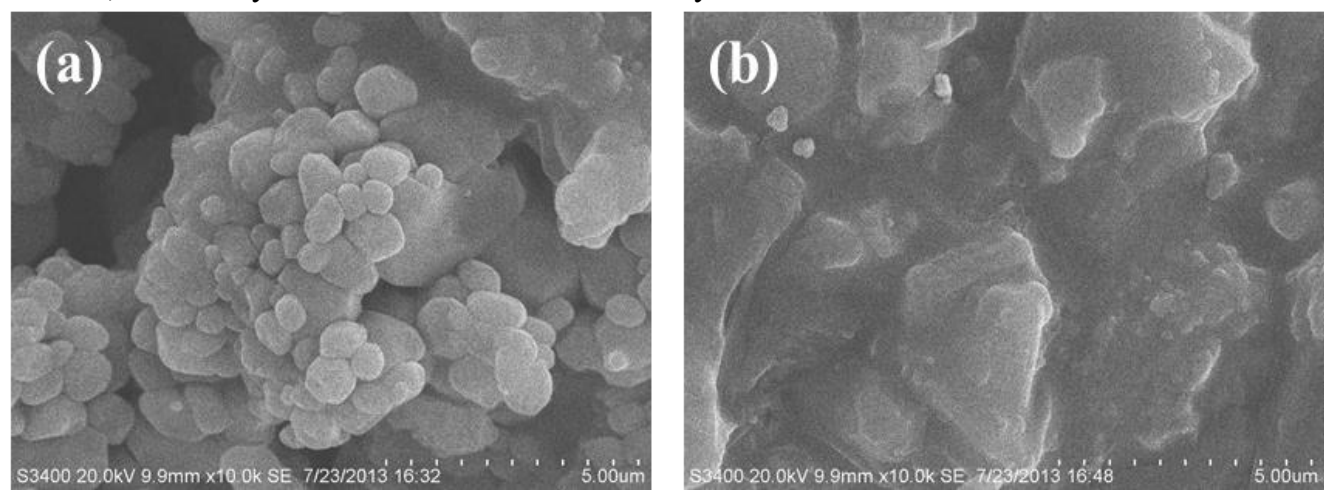

Figure 2. Surface SEM microstructures of coating: (a) ZS-1; (b) ZS-2.

Fig. 2 shows the coating surface SEM microstructures pictures of ZS-1 and ZS-2. It can be seen from the Fig. 2(a) that a lot of tiny particles covered on a large grain which is $\mathrm{ZrSiO} 4$ grain, and the tiny particles can be regarded as $\mathrm{ZrO} 2$ particles. However, in Fig. 2(b), these tiny particles covered on $\mathrm{ZrSiO} 4$ grains were rare. This is because as the mineralizer was added, most of the $\mathrm{ZrO} 2$ transform to $\mathrm{ZrSiO} 4$ completely. And the images displayed that the $\mathrm{ZrSiO} 4$ grains embedded in the glass state, which might be $\mathrm{SiO} 2$ melting. From Fig. 2(b), $\mathrm{SiO} 2$ melting wrapped $\mathrm{ZrSiO} 4$ grains, well filled in the gaps between the grains, which indicated $\mathrm{SiO} 2$ can effectively fill the cracks between the grain boundaries, prevent grain boundary diffusion of oxygen. This improves the oxidation resistance of coating. 


\subsection{Oxidation Resistance}

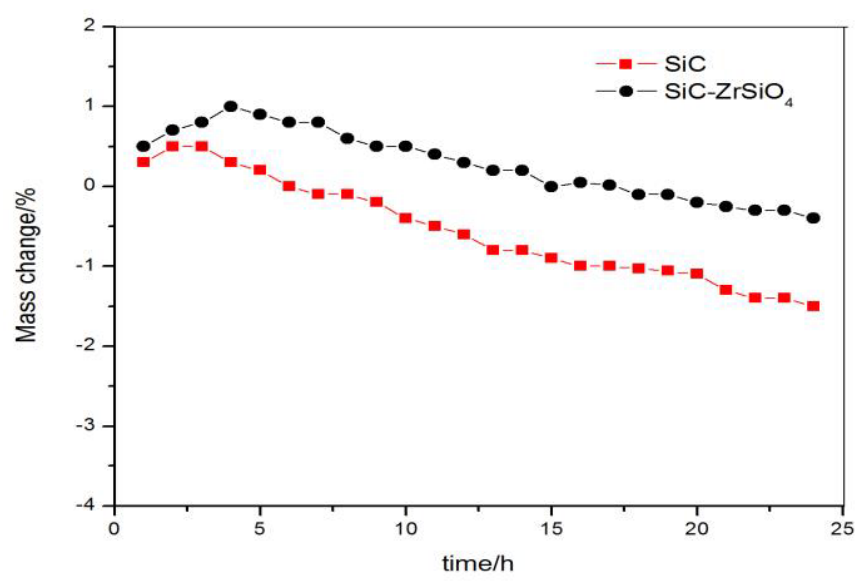

Figure 3. Isothermal oxidation curves for samples of the $\mathrm{ZS}-2$ coating at $1500^{\circ} \mathrm{C}$

Due to the higher synthetic rate of $\mathrm{ZrSiO} 4$, we chose $\mathrm{ZS}-2$ for oxidation resistance test. Fig. 3 shows the isothermal oxidation curves for samples of the coating at $1500^{\circ} \mathrm{C}$. The mass rate of both curves at the beginning of the oxidation was increased first, and then decreased slightly. Mass loss of SiCcoated $\mathrm{C} / \mathrm{C}$ was $1.5 \%$ during $24 \mathrm{~h}$ oxidation, which indicated that the as-prepared $\mathrm{SiC}$ coating could effectively protect $\mathrm{C} / \mathrm{C}$ during the oxidation process. This is because in high temperature air, SiC coating surface generates a dense thin layer of $\mathrm{SiO} 2$, which can effectively block the diffusion of oxygen $[7,8]$. The formation of the $\mathrm{SiO} 2$ was attributed to the reactions displayed in Eqs. (2)

$$
\mathrm{SiC}+2 \mathrm{O} 2 \rightarrow \mathrm{SiO} 2+\mathrm{CO} 2
$$

This explains why the weight had some increase at the start of oxidation experiments. Even though $\mathrm{SiC}$ caoting can effectively protect $\mathrm{C} / \mathrm{C}$, it is not employed in practial application. Because at the temperature above $1400{ }^{\circ} \mathrm{C}$ stage, $\mathrm{SiO} 2$ melted into liquid, can effectively fill the cracks, which can exhibit excellent oxidation resistance, but in the medium temperature stage, the viscosity of $\mathrm{SiO} 2$ is very big, which can not fill the micro-cracks in the coating, and in the environment of high temperature scouring, $\mathrm{SiO} 2$ is easily torn away, so it is necessary to prepare a coating of high temperature oxidation resistant coating on the surface of $\mathrm{SiC}$ layer. From Fig. 3, $\mathrm{ZrSiO} 4 / \mathrm{SiC}$ coating has a better oxidation resistance than $\mathrm{SiC}$ coating and there is almost no mass loss in the progress of oxidation. The mass loss of $\mathrm{ZrSiO} 4 / \mathrm{SiC}$-coated $\mathrm{C} / \mathrm{C}$ was only $0.4 \%$ during $24 \mathrm{~h}$ oxidation. As a result of the preparation of dense $\mathrm{ZrSiO} 4$ ceramic coating, O2- did not easily diffuse into the coating surface, to combine with the $\mathrm{SiO} 2$ liquid glass phase formed at high temperature. This can effectively make up for the microcracks to prevent the diffusion of oxygen. As shown in the Fig. 2(b), $\mathrm{ZrSiO} 4$ grains embeded in $\mathrm{SiO} 2$ glass state, and the coating has no microcracks, so the oxidation rate of the coating depends on the diffusion rate of oxygen in the $\mathrm{ZrSiO} 4$ and $\mathrm{SiO} 2$. At the same time, $\mathrm{SiC}$ used as a buffer layer, also forming a dense $\mathrm{SiO} 2$ layer on the surface in high temperature, can prevent oxygen diffusing, which further improves the property of oxidation resistance.

\subsection{Infrared Characteristics}



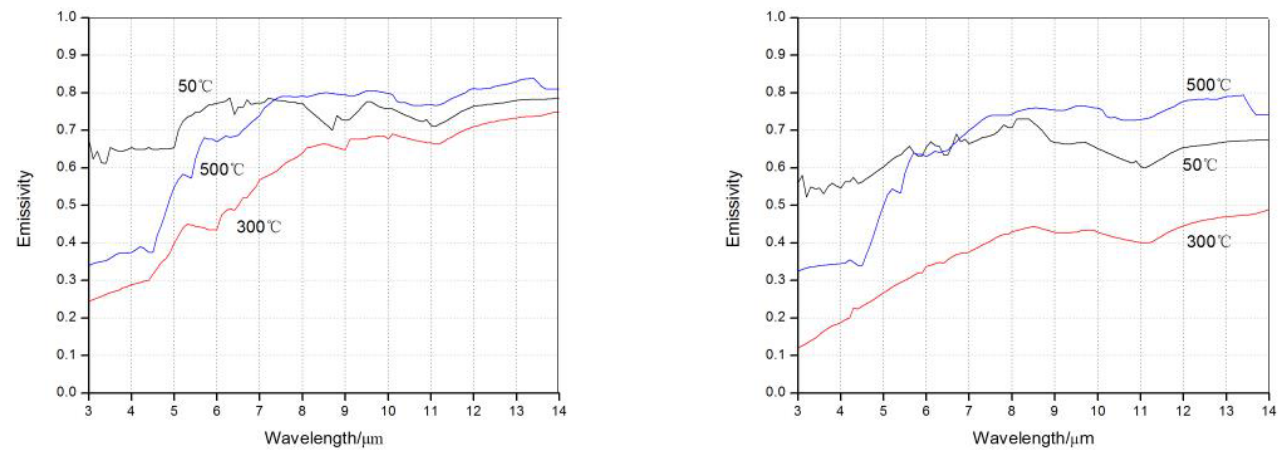

Figure 4. Spectral emissivity curves for $\mathrm{ZrSiO} 4$ coating at different temperature: (a) ZS-1; (b) ZS-2

Figure 4 shows the emissivity curves for $\mathrm{ZrSiO} 4$ coating at $50^{\circ} \mathrm{C}, 300^{\circ} \mathrm{C}$ and $500^{\circ} \mathrm{C}$. It can be seen from the picture that the emissivity of $\mathrm{ZrSiO} 4$ coating was the lowest when the temperature is at $300{ }^{\circ} \mathrm{C}$ and the measured value of infrared emissivity is increasing with the wavelength increase. When the temperature is above $300^{\circ} \mathrm{C}$, the emissivity increases. When the wavelenght is above $7 \mu$ $\mathrm{m}$, the emissivity at $50{ }^{\circ} \mathrm{C}$ is lower than that at $500{ }^{\circ} \mathrm{C}$. Compared with Fig. 4(a) and (b), the emissivity of ZS-2 is lower than ZS-1, overall. From Fig. 4(b), the emissivity of 3-14 $\mu \mathrm{m}$ band of $\mathrm{ZrSiO} 4$ coating is less than 0.8 at different temperature which expresses an excellent infrared characteristic. Kruse et al. [9] according to the experimental results thought that the emissivity decreases with temperature for non-metallic materials. However, in this study, the emissivity of $\mathrm{ZrSiO} 4$ coating presents a different rule. This may be because the residual $\mathrm{ZrO} 2$ changes the trend that the emissivity decreases with temperature increase. When the temperature is above $300^{\circ} \mathrm{C}$, residual $\mathrm{ZrO} 2$ on the emissivity have a significant impact, the residual $\mathrm{ZrO} 2$ more, the temperature higher, the emissivity higher.

Table 2. Average emissivity

\begin{tabular}{|c|c|c|c|c|}
\hline & \multicolumn{4}{|c|}{ The average emissivity } \\
\hline & \multicolumn{2}{|c|}{ ZS-1 } & \multicolumn{2}{|c|}{ ZS-2 } \\
\hline & $3-5 \mu \mathrm{m}$ & $8-14 \mu \mathrm{m}$ & $3-5 \mu \mathrm{m}$ & $8-14 \mu \mathrm{m}$ \\
\hline $50^{\circ} \mathrm{C}$ & 0.65 & 0.71 & 0.55 & 0.64 \\
\hline $300^{\circ} \mathrm{C}$ & 0.28 & 0.68 & 0.18 & 0.43 \\
\hline $500^{\circ} \mathrm{C}$ & 0.38 & 0.79 & 0.35 & 0.74 \\
\hline
\end{tabular}

Table 2 lists average emissivity of ZS-1 and ZS-2 in the 3-5 $\mu \mathrm{m}$ and 8-14 $\mu \mathrm{m}$ wavebands at different temperatures. The emissivity on $8-14 \mu \mathrm{m}$ waveband is higher than the emissivity in $3-5 \mu \mathrm{m}$ waveband at any temperature. From ZS-1 formula, the emissivity of both bands are the lowest with value of 0.28 and 0.68 when the temperature is at $300^{\circ} \mathrm{C}$, while the lowest value of the emissivity of ZS-2 is 0.18 and 0.43 when the temperature is at $300{ }^{\circ} \mathrm{C}$. Compared with ZS-1, the data of ZS-2 emissivity is lower, which indicated that the emissivity of $\mathrm{ZrSiO} 4$ coating declined with the decrease of $\mathrm{ZrO} 2$. This may be because, in $\mathrm{ZS}-1$ formula, many of the remaining $\mathrm{ZrO} 2$ will cause vibration strongly and affect absorption of infrared radiation, thereby increasing the infrared emissivity of the coating. And the effect of $\mathrm{ZrO} 2$ on the emissivity is more evident in the high temperature. Before $300^{\circ} \mathrm{C}$, the emissivity of $\mathrm{ZrSiO} 4$ is mainly determined by the temperature, so the emissivity declease with the temperature increase. Due to the fact that higher the temperature of an object, the better the crystallinity and periodicity of crystal, so emissivity declined; After $300{ }^{\circ} \mathrm{C}, \mathrm{ZrO} 2$ content on the emissivity plays a main role, so at $500^{\circ} \mathrm{C}$, the emissivity has increased significantly. 


\section{Conclusions}

$\mathrm{ZrSiO} 4$ ceramic coatings were prepared by pressureless sintering in a argon atmosphere at $1500^{\circ} \mathrm{C}$. With the addition of mineralizer, $\mathrm{ZrSiO} 4$ synthesis rate increased from $68.58 \%$ to $83.47 \%$. The antioxidant performance of the prepared $\mathrm{SiC}$ layer and $\mathrm{SiC}-\mathrm{ZrSiO} 4$ coating at $1500{ }^{\circ} \mathrm{C}$ in air for $24 \mathrm{~h}$ with a mass loss was $1.5 \%$ and $0.4 \%$, respectively. The average infrared emissivity of $\mathrm{ZrSiO} 4$ coating in the 3-5 $\mu \mathrm{m}$ and 8-14 $\mu \mathrm{m}$ wavebands decreased with increase temperature. The emissivity of $\mathrm{ZrSiO} 4$ coating declined with the decrease of $\mathrm{ZrO} 2$, and the infrared emissivity of $\mathrm{ZrSiO} 4$ coating in the 3-5 $\mu$ $\mathrm{m}$ and $8-14 \mu \mathrm{m}$ wavebands was 0.55 and 0.64 at $50^{\circ} \mathrm{C}, 0.18$ and 0.43 at $300^{\circ} \mathrm{C}, 0.35$ and 0.74 at $500^{\circ} \mathrm{C}$, respectively.

\section{Acknowledgements}

The present work was supported by the Funding of Jiangsu Innovation Program for Graduate Education (the Fundamental Research Funds for the Central Universities), KYLX15_0308 and Priority Academic Program Develop-ment of Jiangsu Higher Education Institutions.

\section{References}

1. J. Zueco, F. Alhama., J. Quant. Spectrosc. Radiat. Transfer, 14, 7 (2006)

2. Y. T. Jiang, Y. Wang. Infrared Technology, 25, 5 (2003)

3. Y. Shi, X.X. Huang, D.S. Yan, J. Eur. Ceram. Soc., 13, 2 (1994)

4. Y. Kubeta, S. Yamamoo, T. Mori, J. Ceram. Soc. Jpn., 102, 1 (1994)

5. J. Wen, S. Z. Sun, Bulletin of The Chinese Ceramic Socity, 18, 6 (1999)

6. R. A. Eppler, J. Am. Ceram. Soc, 53, 8 (1970)

7. J. D Buekley, D. D Edie, Noyes Publications, USA (1993)

8. O. V. Mazurin, Handbook of glass data-Part A, Silica glass and binary silicat glasses, 15, (1985).

9. W. P. Kruse, D. Laurence, McGlauchlin, Elements of Infrared Technology. New York: Wiley, (1962) 